\title{
Frequency of Burnout, Sleepiness and Depression in Emergency Medicine Residents with Medical Errors in the Emergency Department
}

Alireza Aala ${ }^{1}$, Jafar Tabrizi ${ }^{2}$, Fatemeh Ranjbar ${ }^{3}$, Samad Shams Vahdati ${ }^{4}$, Neda Mohammadi ${ }^{5}$

1.Dept. of Emergency Medicine, Tuberculosis and Lung Disease Research Center, Tabriz University of Medical Sciences, Tabriz, Iran

2.Dept. of Management and Public Health, Faculty of Health and Nutrition, Tabriz University of Medical Sciences, Tabriz, Iran

3.Dept. of Psychiatry, Neuroscience Research Center, Faculty of Medicine, Tabriz University of Medical Sciences, Tabriz, Iran

4.Dept. of Emergency Medicine, Faculty of Medicine, Tabriz University of Medical sciences, Tabriz, Iran 5.Medical Philosophy and History Research Center, Tabriz University of Medical Sciences, Tabriz, Iran

\begin{abstract}
Aims: Medical error is a great concern of the patients and physicians. It usually occurs due to physicians' exhaustion, distress and fatigue. In this study, we aimed to evaluate frequency of distress and fatigue among emergency medicine residents reporting a medical error.

Materials and Methods: The study population consisted of emergency medicine residents who completed an emailed questionnaire including self-assessment of medical errors, the Epworth Sleepiness Scale (ESS) score, the Maslach Burnout Inventory, and PRIME-MD validated depression screening tool.

Results: In this survey, 100 medical errors were reported including diagnostic errors in 53, therapeutic errors in 24 and following errors in 23 subjects. Most errors were reported by males and third year residents. Residents had no signs of depression, but all had some degrees of sleepiness and burnout. There were significant differences between errors subtypes and age, residency year, depression, sleepiness and burnout scores $(p<0.0001)$.

Conclusion: In conclusion, residents committing a medical error usually experience burnout and have some grades of sleepiness that makes them less motivated increasing the probability of medical errors. However, as none of the residents had depression, it could be concluded that depression has no significant role in medical error occurrence and perhaps it is a possible consequence of medical error.
\end{abstract}

Keywords: Residents; Medical error; Burnout; Sleepiness; Depression

\section{Corresponding author:}

Neda Mohammadi

Medical Philosophy and History Research Center, Tabriz University of Medical Sciences, Tabriz, Iran Zip code: 5166618573l; Tel: +98 411-3357767l; Fax: +98 411-3344021; E-mail: dr.nmohammadi@yahoo.com

Receive date: 2014-03-01 | Accept date: 2014-03-18 | Publish date:

2014-04-06 DOI: 10.7575/aiac.abcmed.14.02.02.09 


\section{Introduction}

Medical errors are considered a major concern among physicians and occur at high rates (1-3). Previous studies have reported medical errors with different incidences from $5 \%$ to $10 \%$ and even $50 \%$ (4-7). Medical errors include errors in prescribing the right treatment or right dosage, diagnosing and identification of patient and or misdiagnosis or late diagnosis $(8,9)$.

Medical errors are common among residents because of long shifts, job stress, sleep deprivation and subsequent fatigue (10-14). Due to physical, emotional, and mental exhaustion, residents are more predisposed to burnout $(15,16)$. Also, it is shown that the main cause for self-reported medical errors in residents is burnout $(17,18)$.

Emergency departments are particularly stressful work environments for patients and physicians (19). This stressful environment along with long time shifts, sleepiness and fatigue makes the emergency medicine increase the probability of medical error in these residents. In this study, we aimed to evaluate the relation between distress and fatigue, as causes of medical errors, with selfreported medical errors in emergency medicine residents.

\section{Methods}

All students enrolled in emergency medicine residency program were invited to participate. In this web-based study, we sent an anonymous email to all emergency medicine residents asking for medical errors performed by them in emergency department, Imam Reza Hospital, Tabriz, Iran during a 6 month period between March and August 2012. Participants reported 100 self-reported medical errors. Subjects provided written informed consent. Study population comprised of all emergency medicine residents in first, second and third years of residency. Twenty-four hour a day was divided into two 12-hour shifts. In each shifts there was at least 8 residents making 2880 shifts in a 6 month period providing an appropriate situation for evaluating medical errors. At the end of the each month, residents were provided with a distress and fatigue questionnaire through email and were asked about the medical errors occurred in the opinion of the residents. Residents reported their medical errors with the question, "During last month, did you perpetrate a medical error?" In the questionnaire, it was explained that we included errors recognized by residents as medical errors rather than events that harmed patients. This error should be grouped into diagnostic errors, treatment errors and errors in following patients (including following patients from the previous shifts and the error of not following the accurate application of patients' orders).

After collecting the questionnaires, those with medical errors were evaluated for having distress or fatigue. Distress and fatigue was defined in three subtypes: depression, sleepiness and burnout. Depression was evaluated by PRIME-MD depression screening instrument, Burnout was evaluated by Maslach burnout inventory questionnaire and sleepiness was evaluated by Epworth sleepiness score. The person analyzing the questionnaires was blinded to the subjects' personal information.

Data analysis

Statistical analyses were performed using the Statistical Package for Social Sciences, version 17.0 (SPSS, Chicago, Illinois). Quantitative data were presented as mean \pm standard deviation (SD), while qualitative data were demonstrated as frequency and percent (\%). The categorical parameters were compared by $\chi 2$ tests or Fisher's exact test, and the continuous variables were compared by Student's t-tests and one-Way ANOVA for independent continuous scale data and MannWhitney $U$ test for nonparametric data when 
appropriate. A p value $<0.05$ was considered statistically significant.

\section{Results}

In this survey, 100 medical errors were reported by emergency medicine residents. Medical errors were diagnostic errors in 53, therapeutic errors in $24 \%$ and following errors in $23 \%$ cases. Most errors were reported by males and residents in third year (Table 1).

Table 1: Demographic findings of subjects reporting medical errors.

\begin{tabular}{|c|c|}
\hline Age (Mean \pm SD) & $29.1 \pm 2.23$ \\
\hline Male sex (n) & 71 \\
\hline Married (n) & 50 \\
\hline \multicolumn{2}{|l|}{ Residency year (n) } \\
\hline First year & 35 \\
\hline Second year & 26 \\
\hline Third year & 39 \\
\hline $\begin{array}{ll}\text { Depression } & \text { score } \\
(\text { Mean } \pm S D) & \end{array}$ & $2.62 \pm 1.62$ \\
\hline Sleepiness (Mean \pm SD) & $12.33 \pm 1.63$ \\
\hline Burnout (Mean士SD) & $34.02 \pm 8.96$ \\
\hline
\end{tabular}

None of patients had depression score $<5$ and diagnosed with depression. Sixty percent had mild and $40 \%$ had severe sleepiness scores. Subjects were at risk of severe burnout in $45 \%$ and very severe burnout in $55 \%$ of the subjects.

Table 2 demonstrates findings between medical errors subtypes. There were significant differences between errors subtypes and age, residency year, depression, sleepiness and burnout scores. Following errors, in comparison to diagnostic and therapeutic errors, was occurred significantly in older subjects with lower depression and burnout score and higher sleepiness score $(p<0.0001)$; however, there was no differences between diagnostic and therapeutic errors.
Table 2: Demographic and distress and fatigue findings between medical errors subtypes.

\begin{tabular}{|c|c|c|c|c|}
\hline & $\begin{array}{c}\text { Diagno } \\
\text { stic } \\
\text { error }\end{array}$ & $\begin{array}{c}\text { Therap } \\
\text { eutic } \\
\text { error }\end{array}$ & $\begin{array}{c}\text { Followi } \\
\text { ng } \\
\text { error }\end{array}$ & $\begin{array}{c}P \\
\text { value }\end{array}$ \\
\hline Age & $\begin{array}{c}28.50 \pm \\
2.07\end{array}$ & $\begin{array}{c}28.62 \pm 2 \\
.22\end{array}$ & $\begin{array}{c}30.95 \pm \\
1.58\end{array}$ & $\begin{array}{l}<0.0 \\
01^{*}\end{array}$ \\
\hline Male & $\begin{array}{c}37 \\
(69.8 \%) \\
\end{array}$ & $\begin{array}{c}16 \\
(66.7 \%)\end{array}$ & $\begin{array}{c}18 \\
(78.3 \%)\end{array}$ & 0.65 \\
\hline $\begin{array}{c}\text { Reside } \\
\text { ncy } \\
\text { year }\end{array}$ & & & & \\
\hline First & $\begin{array}{c}23 \\
(43.4 \%)\end{array}$ & $\begin{array}{c}12 \\
(50 \%)\end{array}$ & 0 & $\begin{array}{l}<0.0 \\
01^{*}\end{array}$ \\
\hline Second & $\begin{array}{c}14 \\
(26.4 \%) \\
\end{array}$ & $\begin{array}{c}8 \\
(33.3 \%) \\
\end{array}$ & $\begin{array}{c}4 \\
(17.4 \%) \\
\end{array}$ & \\
\hline Third & $\begin{array}{c}16 \\
(30.2 \%)\end{array}$ & $\begin{array}{c}4 \\
(16.7 \%)\end{array}$ & $\begin{array}{c}19 \\
(82.6 \%)\end{array}$ & \\
\hline $\begin{array}{c}\text { Depres } \\
\text { sion }\end{array}$ & $\begin{array}{c}2.94 \pm 1 . \\
59 \\
\end{array}$ & $\begin{array}{c}3.41 \pm 1 . \\
10 \\
\end{array}$ & $\begin{array}{c}1.04 \pm 1 . \\
02\end{array}$ & $\begin{array}{l}<0.0 \\
01^{*}\end{array}$ \\
\hline $\begin{array}{c}\text { Sleepin } \\
\text { ess }\end{array}$ & $\begin{array}{c}11.81 \pm \\
1.28\end{array}$ & $\begin{array}{c}11.66 \pm 1 \\
.23\end{array}$ & $\begin{array}{c}14.21 \pm \\
1.31\end{array}$ & $\begin{array}{l}<0.0 \\
01 *\end{array}$ \\
\hline $\begin{array}{c}\text { Burnou } \\
t\end{array}$ & $\begin{array}{c}36.37 \pm \\
7.95\end{array}$ & $\begin{array}{c}36.95 \pm 8 \\
.97\end{array}$ & $\begin{array}{c}25.52 \pm \\
5.45\end{array}$ & $\begin{array}{l}<0.0 \\
01^{*}\end{array}$ \\
\hline
\end{tabular}

* $\mathrm{P}$ is two-sided significant.

\section{Discussion}

The occurrence of errors is prominent among physicians. Such errors threaten patient safety and are found to be related to physician burnout and emotional problems (20). Severe medical errors with severe consequences occur usually in intensive care units, operation room and emergency department due to high workload and long shifts. Previous studies have reported a great association between the workload in a shift and negative safety outcomes $(21,22)$. The effects of stressful incidents on emergency department staff can be profound. Witnessing aggression, violence or the death of patients, or participating in resuscitation, can be emotionally and physically demanding. This stressful situation can lead to medical errors. 
In this study among emergency medicine residents, we observed that all residents reporting the medical error were at risk of burnout and suffered sleepiness but reported no sign of depression. Medical errors in following patients occurred in subjects with lower depression and burnout scores and higher sleepiness score. We observed that mostly male subjects and those in third year of residency reported medical errors. This could be due to the fact that residents with more experience could distinguish between a real and perceived medical error and also female subjects were most likely to worry about the consequences of the reporting a medical error unlike the male residents.

Previous studies have reported depression among residents between $7 \%-56 \%$ (23-26). The stressful situation, long shifts and heavy workload in the residency can trigger depression. Also, committing medical errors may also lead to the physician's depression (27). West and colleagues in two different studies $(17,28)$ reported depression symptoms in $68.7 \%$ and $63.33 \%$ of residents reporting medical error. With lower incidence rate, Fehrenkopt and colleagues (18) reported depression in $20 \%$ of residents. Unlike these studies, in our study, none of the residents reporting the medical error had depression. This could be due to self-reported questionnaires which would accompany with underestimating the real situation. It is possible that the real prevalence of depression be higher than the current values.

In our study, we observed that all residents reporting medical error had mild or severe sleepiness which contributes to the errors occurrence. Among these errors, those due to failure to follow patients usually occurred in subjects with more sleep deprivation. It has been shown that lack of sleep of workers, can result in careless behavior that jeopardizes safety (29). Due to the sleep deprivation and fatigue in the residency, it is possible that residents lose their concern for their work and become less careful toward their patients. Additionally, extended-duration work along with the high level of chronic partial sleep deprivation may account for the high base rate of attentional failures and impaired performance and safety (14). Shift length for emergency medicine residents are long and interrupt normal sleep periods which can deteriorate residents' performance and the quality of their patient care (4).

Residency period is stressful and this stress is unavoidable, but residents do not become immune to the stress, and are often ill prepared and under-supported to cope with them. These shortcomings can result in burnout (30). We observed that as a result of long shifts with high workload and the stressful situation of the emergency department, as well as sleepiness, all our residents reporting medical errors experienced some degrees of burnout.

\section{Conclusion}

In conclusion, residents committing a medical error are usually burned out and have some grades of sleepiness that makes them less motivated increasing the probability of medical error. However, as none of the residents had depression, it could be concluded that depression has no significant role in medical error occurrence and perhaps it is rather a possible consequence of medical error.

\section{Acknowledgments}

This research was financially supported by Tuberculosis and Lung Disease Research Center, Tabriz University of Medical Sciences, Iran. The authors have no conflicts of interest.

\section{Conflicts of interest}

The authors declare that they have no conflict of interest. 


\section{References}

1. Hayward RA, Hofer TP. Estimating hospital deaths due to medical errors: preventability is in the eye of the reviewer. JAMA. 2001;286:415-20.

2. Reasons J. Human error: models and management. BMJ. 2000;320(7237):768-770.

3. Vincent C, Neale G, Woloshynowych M. Adverse events in British hospitals: preliminary retrospective record review. BMJ. 2001;322:517-9.

4. Chaudhry $\mathrm{SI}$, Olofinboba KA, Krumholz HM. Detection of errors by attending physicians on a general medicine service. J Gen Intern Med. 2003;18:595-600.

5. Baker GR, Norton PG, Flintoft V, Blais R, Brown A, Cox J, et al. The Canadian Adverse Events Study: the incidence of adverse events among hospital patients in Canada. CMAJ. 2004; 170:1678-1686.

6. Graf J, von den Driesch A, Koch KC, Janssens U. Identification and characterization of errors and incidents in a medical intensive care unit. Acta Anaesthesiol Scand. 2005;49:930-939.

7. Andrews LB, Stocking C, Krizek T, Gottlieb L, Krizek C, Vargish T, et al. An alternative strategy for studying adverse events in medical care. Lancet. 1997;349:309-313.

8. Leape LL, Brennan TA, Laird N, Lawthers AG, Localio AR, Barnes BA, et al. The nature of adverse events in hospitalized patients. Results of the Harvard Medical Practice Study II. N Engl J Med. 1991; 324:377-384.

9. Thomas EJ, Studdert DM, Burstin HR, Orav EJ, Zeena T, Williams EJ, et al. Incidence and types of adverse events and negligent care in Utah and Colorado. Med Care. 2000; 38:261-271.

10. Mizrahi T. Managing medical mistakes: ideology, insularity, and accountability among internists-in-training. Soc Sci Med. 1984; 19:135-146.

11. Wu AW, Folkman S, McPhee SJ, Lo B. Do house officers learn from their mistakes? JAMA. 1991; 265:2089-2094.

12. Lockley SW, Cronin JW, Evans EE, Cade BE, Lee CJ, Landrigan CP, et al. Effects of reducing interns' weekly work hours on sleep and attention failures. N Engl J Med. 2004; 351:1829-37.

13. Barger LK, Ayas NT, Cade BE, Cronin JW, Rosner B, Speizer FE, et al. Impact of extended-duration shifts on medical errors, adverse events, and attentional failures. PLoS Med. 2006; 3:e487.

14. Lockley SW, Barger LK, Ayas NT, Rothschild JM, Czeisler CA, Landrigan CP, et al. Effects of health care provider work hours and sleep deprivation on safety and performance. Jt Comm J Qual Patient Saf. 2007; 33(11 Suppl):7-18.

15. Ozyurt A, Hayran O, Sur H. Predictors of burnout and job satisfaction among Turkish physicians. Q J Med. 2006; 99:161-9.

16. De Oliveira GS, Ahmed S, Stock MC, Harter RL, Almeida MD, Fitzgerald PC, et al. High incidence of burnout in academic chairpersons of anesthesiology: Should we be taking better care of our leaders? Anesthesiology. 2011; 114:181-93.

17. West CP, Huschka MM, Novotny PJ, Sloan JA, Kolars JA, Habermann TR, et al. Association of perceived medical errors with resident distress and empathy: a prospective longitudinal study. JAMA. 2006; 296:1071-8.

18. Fahrenkopf AM, Sectish TC, Barger LK, Sharek PJ, Lewin D, Chiang VW, et al. Rates of medication errors among depressed and burnt out residents: prospective cohort study. BMJ. 2008; 336:488-91.

19. Burroughs TE, Waterman AD, Gallagher TH, Waterman B, Adams D, Jeffe DB, et al. Patient concerns about medical errors in emergency departments. Acad Emerg Med. 2005; 12:57-64.

20. Shanafelt TD, Balch CM, Bechamps G, Russell T, Dyrbye L, Satele D, et al. Burnout and medical errors among American surgeons. Ann Surg. 2010; 251:995-1000. 
21. Needleman J, Buerhaus P, Mattke S, Stewart M, Zelevinsky K. Nurse-staffing levels and the quality of care in hospitals. N Engl J Med. 2002; 346(22):1715-1722.

22. Aiken LH, Clarke SP, Sloane DM, Sochalski J, Silber JH. Hospital nurse staffing and patient mortality, nurse burnout, and job dissatisfaction. JAMA. 2002; 288(16):1987-1993.

23. Shanafelt TD, Bradley KA,Wipf JE, Back AL. Burnout and self-reported patient care in an internal medicine residency program. Ann Intern Med. 2002; 135:358-67.

24. Bellini LM, BaimeM, Shea JA. Variation ofmood and empathy during internship. JAMA. 2002; 287:3143-6.

25. Gopal R, Glasheen JJ,Miyoshi TJ, Prochazka AV. Burnout and internal medicine resident work-hour restrictions. Arch Intern Med. 2005; 165:2595-600.

26. Goitein L, Shanafelt TD, Wipf JE, Slatore CG, Back AL. The effects of work-hour limitations on resident well-being, patient care, and education in an internal medicine residency program. Arch Intern Med. 2005; 165:2601-6.

27. Wu AW. Medical error: the second victim. BMJ. 2000; 320:726-7.

28. West CP, Tan AD, Habermann TM, Sloan JA, Shanafelt TD. Association of resident fatigue and distress with perceived medical errors. JAMA. 2009; 302:1294-300.

29. Komatsu H. Referenced data about the relationships between sleep loss and safety. J Sci Labour. 2003; 79:17-29 (in Japanese with English abstract).

30. Pines AM, Kanner AD. Nurses' burnout: lack of positive conditions and presence of negative conditions as two independent sources of stress. J Psychosoc Nurs Ment Health Serv. 1982; 20:30-5. 